\title{
A Meta-analysis of Sphaeranthus indicus and Garcinia mangostana Products on Cardiometabolic Outcomes in Obese Patients
}

\author{
W. PHIMARN*, K. WICHAIYO, B. SUNGTHONG AND K. SARAMUNEE \\ Social Pharmacy Research Unit, Faculty of Pharmacy, Mahasarakham University, Kantharawichai, Maha Sarakham, 44150, \\ Thailand
}

Phimarn et al.: Meta-analysis of $S$. indicus and G. mangostana on cardiometabolic outcomes

\begin{abstract}
This study aimed to assess the efficacy of Sphaeranthus indicus and Garcinia mangostana in improving anthropological parameters, lipid profile, blood glucose and blood pressure in obese patients. The databases used included PubMed, Scopus, Web of Science from inception to March 2019. For this analysis, a randomized placebo versus Sphaeranthus indicus and Garcinia mangostana intervention trials were selected and performed a quality assessment of the retrieved data studied using Jadad's scoring and Cochrane's risk of bias assessment. Three studies (215 participants) met inclusion criteria. Metaanalysis revealed a reduction in body weight (weight mean difference; $-3.84 \mathrm{~kg} ; 95$ \% CI: $-\mathbf{3 . 9 8}, \mathbf{- 3 . 7 0}$ ), BMI (weight mean difference $-1.56 \mathrm{~kg} / \mathrm{m}^{2} ; 95 \% \mathrm{CI}$ : $-1.65,-1.47$ ), waist circumference (weight mean difference $\mathbf{- 5 . 9 0} \mathrm{cm} ; 95 \% \mathrm{CI} ; \mathbf{- 6 . 3 6}, \mathbf{- 5 . 4 3})$. Similar results were observed for low density lipoprotein-cholesterol (weight mean difference $\mathbf{- 1 0 . 7 4} \mathrm{mg} / \mathrm{dl} ; 95 \% \mathrm{CI}$; -19.04, -2.44), total cholesterol (weight mean difference $\mathbf{- 2 2 . 0 5} \mathrm{mg} / \mathrm{dl}$; $95 \%$ CI -32.33, -11.76), triglyceride (weight mean difference $\mathbf{- 2 7 . 4 0 ~ m g / d l ; ~} 95 \%$ CI -30.55, -24.24) and increased high density lipoprtein significantly (weight mean difference $2.32 \mathrm{mg} / \mathrm{dl} ; 95 \%$ CI 0.56, 4.07). No serious adverse effects were found in either the Sphaeranthus indicus and Garcinia mangostana treated groups or comparator groups. It was concluded that Sphaeranthus indicus and Garcinia mangostana improved anthropological parameters and lipid profile.
\end{abstract}

Key words: $S$. indicus and G. mangostana, anthropological parameters, lipid profile, blood glucose, blood pressure

Cardiovascular disease (CVD) is the single leading cause of mortality worldwide ${ }^{[1]}$ and also the most common cause of morbidity and mortality in individuals among patients with metabolic profile abnormality ${ }^{[2]}$. Metabolic profile abnormality is related to the elevation of glycemic profile, lipid profile, blood pressure and anthropological parameters. CVD and metabolic profile abnormality could potentially be prevented or managed by addressing modifiable risk factors, for instance, physical activity and $\operatorname{diet}^{[3]}$. Therefore, effective prevention strategies are urgently needed to reduce mortality from $\mathrm{CVD}^{[4]}$. Earlier studies reported that a herbal formulation, Meratrim consisting of extracts of the flower heads from Sphaeranthus 
indicus L. (Asteraceae) and the fruit rinds of Garcinia mangostana L. (Clusiaceae) demonstrated significantly improved metabolic outcomes in obese populations ${ }^{[5]}$. Furthermore, experimental studies also showed protective effects of $S$. indicus and G. mangostana products, including reduction in peroxisome proliferator-activated receptor gamma $(\operatorname{PPAR} \gamma)^{[6]}$ and down regulation fatty acid synthetase (FAS) resulting to alter de novo lipogenesis ${ }^{[7]}$. Preclinical trials have suggested that intake of $S$. indicus and G. mangostana products has been decreased anthropological outcomes $^{[8]}$. However, these studies were performed in a small number of participants and there was no previous systematic review or meta-analysis of effects of $S$. indicus and $G$. mangostana products on cardiometabolic outcomes. Therefore, a systematic review and meta-analysis was conducted to compare the effectiveness and safety of $S$. indicus and G. mangostana products on cardiometabolic outcomes in obese participants.

This systematic review was conducted according to the Cochrane Collaboration framework guidelines ${ }^{[9]}$, and reporting follows the PRISMA Statement ${ }^{[10]}$. All reports of double blind randomized controlled trials of $S$. indicus and G. mangostana in obese participants were identified through a systematic literature search of PubMed, Scopus and Web of Science databases. All databases were searched right from their inceptions to March 2019. The following MeSH terms were used: Sphaeranthus indicus, Garcinia mangostana, Sphaeranthus indicus and Garcinia mangostana, $S$. indicus, G. mangostana, obesity, obese, anthropological parameter, body weight, body mass index (BMI), waist circumference. No language restriction was imposed. References of papers derived for full text review were scanned to identify potential studies not indexed in the above databases.

The present study included only reports that were, double blind randomized controlled trial of $S$. indicus and G. mangostana against placebo in obese patients, the duration of the study was at least $8 \mathrm{w}$ and reporting at least one outcome measures in terms of body weight, BMI, waist circumference, lipid profiles, blood glucose, and blood pressure.

All titles and abstracts were scanned based on inclusion criteria. Full-text articles of the potential studies were subsequently assessed independently by two

*Address for correspondence

E-mail: wiraphol.p@msu.ac.th

May-June 2020 researchers. Disagreements between these reviewers were resolved by discussions with a senior researcher. All data were independently extracted by these two researchers using a standardized extraction form. The following information was sought from each article, author, year of publication, type of study design, patient and intervention characteristics, sample size, duration of therapy, and outcome measurements.

Studies included in this review were assessed for methodological quality using the Cochrane risk of bias 2.0 tool $^{[11]}$, which contained 5 domains; bias arising from the randomization process, bias due to deviations from intended interventions, bias due to missing outcome data, bias in measurement of the outcome, bias in selection of the reported result. The overall risk of bias for each study was classified as low risk of bias (low risk of bias for all domains), some concern (some concerns in at least one domain and no high risk of bias in any domain), and high risk of bias (high risk of bias in at least one domain or some concerns for multiple domains in a way that substantially lowers confidence in the results). Disagreements between the reviewers were settled through discussion and consensus with a third party.

Primary outcomes were anthropological parameters, lipid profile, blood glucose and blood pressure. Secondary outcomes were laboratory measurements such as liver function test and renal function test and adverse events. Pooled effects were calculated and stratified according to outcomes data. Summary statistics of continuous outcomes were expressed as weighted mean difference (WMD) with $95 \%$ confidence intervals (CI), whereas summary statistics dichotomous outcomes were expressed as a risk ratio (RR) with $95 \%$ CI. Statistical heterogeneity between studies was assessed using the chi-squared test and $\mathrm{I}^{2}$. Significant difference for heterogeneity test was considered at $\mathrm{p}<0.05$, and substantial heterogeneity was represented by $\mathrm{I}^{2}$ of $50 \%$ or more ${ }^{[11]}$. If there was evidence of high heterogeneity, attempts were made to explore the reason and subgroup analyses were performed if possible. The

This is an open access article distributed under the terms of the Creative Commons Attribution-NonCommercial-ShareAlike 3.0 License, which allows others to remix, tweak, and build upon the work non-commercially, as long as the author is credited and the new creations are licensed under the identical terms

Accepted 10 April 2020

Revised 06 January 2020 Received 04 July 2019 Indian J Pharm Sci 2020;82(3):527-532 
random effects model was used if the included studies were heterogeneous; alternatively, the fixed effects model was used if homogeneity was found. Publication bias was evaluated using a funnel plot for a particular outcome ${ }^{[12]}$.

The PRISMA flow diagram of studies is shown in fig. 1. The 103 related articles were identified through database searching. After duplication removal, 8 articles were eligible for further screening based on title and abstract screened. A total of 5 articles were excluded after full

\begin{tabular}{|c|c|}
\hline \multicolumn{2}{|c|}{ Articles identified through database search $(n=103)$} \\
\hline & $\begin{array}{l}\text { Excluded by title and abstract: } \\
\text { - } \quad \text { Duplicated }(n=65) \\
\text { - } \quad \text { Animal studies }(n=30)\end{array}$ \\
\hline \multicolumn{2}{|c|}{ Full-text articles assessed for eligibility $(\mathrm{n}=8)$} \\
\hline & $\begin{array}{l}\text { Excluded article: } \\
\text { - } \quad \text { Reviews }(n=3) \\
\text { - } \quad \text { Not anthropological outcomes }(n=2)\end{array}$ \\
\hline \multicolumn{2}{|l|}{$\nabla$} \\
\hline $\mathrm{RCT} s$ & included in meta-analysis $(n=3)$ \\
\hline
\end{tabular}

Fig. 1: Flow diagram for selection of trials text review. Therefore, 3 articles were included in this study ${ }^{[5,13,14]}$.

The characteristics and methodological quality of included studies are summarized in Table 1. All included studies were conducted in India. Periods of study ranged from year 2010 to 2015. All studies were not multicenter with double blind randomized controlled trial and enrolled sample size less than 100 patients. A total of 215 participants were involved including overweight and obese participants. The age of included patients ranged from 21 to $50 \mathrm{y}$. All studies used herbal blend comprises of extracts from $S$. indicus and G. mangostana in a 3:1 ratio. A final product containing at least $3 \%$ 7-hydroxyfrullanolide and $2 \% \alpha$-mangostin. All included studies administered $S$. indicus and G. mangostana products at $800 \mathrm{mg} / \mathrm{d}$ and the treatment courses ranged from 8 to $16 \mathrm{w}$. For methodological quality of included studies, all were high quality trials (Jadad score $>3$ points) with rated low risk of bias (Tables 1 and 2).

Three trials ${ }^{[5,13,14]}$ involving a total of 215 patients reported clinical therapeutic efficacy of $S$. indicus and $G$. mangostana products on the treatment of

TABLE 1: CHARACTERISTIC OF THE INCLUDED STUDIES

\begin{tabular}{|c|c|c|c|c|c|c|c|}
\hline \multirow[t]{2}{*}{ Study (year) } & \multirow[t]{2}{*}{$\begin{array}{l}\text { Study } \\
\text { design }\end{array}$} & \multirow[t]{2}{*}{ Duration } & \multirow[t]{2}{*}{ Participants } & \multicolumn{2}{|c|}{ Treatment characteristic } & \multirow[t]{2}{*}{ Outcomes } & \multirow[t]{2}{*}{$\begin{array}{l}\text { Jadad } \\
\text { score }\end{array}$} \\
\hline & & & & Treatment (n) & control (n) & & \\
\hline $\begin{array}{l}\text { Stern } \\
\text { et al., } \\
2013 A^{[13]}\end{array}$ & DRCT & 8 weeks & $\begin{array}{c}\text { Obese (BMI 30-40 } \\
\left.\mathrm{kg} / \mathrm{m}^{2}\right)\end{array}$ & $\begin{array}{c}\text { S. indicus } \\
\text { G. mangostana } \\
(3: 1 \text { ratio) } 400 \mathrm{mg} \\
\text { twice daily }(\mathrm{n}=30)\end{array}$ & $\begin{array}{l}\text { Placebo twice } \\
\text { daily }(n=30)\end{array}$ & $\begin{array}{c}\text { BW, BMI, WC, SBP, } \\
\text { DBP. FBS, LDL, HDL, } \\
\text { TC, TG, LFT, AEs }\end{array}$ & 5 \\
\hline $\begin{array}{l}\text { Stern } \\
\text { et al., } \\
2013 B^{[14]}\end{array}$ & $\mathrm{DRCT}$ & 8 weeks & $\begin{array}{c}\text { Obese (BMI 30-40 } \\
\left.\mathrm{kg} / \mathrm{m}^{2}\right)\end{array}$ & $\begin{array}{l}\text { S. indicus } \\
\text { G. mangostana } \\
(3: 1 \text { ratio }) 400 \\
\text { twice daily }(\mathrm{n}=49)\end{array}$ & $\begin{array}{l}\text { Placebo twice } \\
\text { daily }(n=46)\end{array}$ & $\begin{array}{c}\text { BW, BMI, WC, SBP, } \\
\text { DBP. FBS, LDL, HDL, } \\
\text { TC, TG, LFT, RFTs, } \\
\text { Hematology, AEs }\end{array}$ & 5 \\
\hline $\begin{array}{l}\text { Kudiganti et } \\
\text { al., 2016[5] }\end{array}$ & $\mathrm{DRCT}$ & 16 weeks & $\begin{array}{c}\text { Obese and } \\
\text { overweight (BMI } \\
\left.27-32 \mathrm{~kg} / \mathrm{m}^{2}\right)\end{array}$ & $\begin{array}{c}\text { S. indicus } \\
\text { G. mangostana } \\
400 \text { twice daily } \\
(n=30)\end{array}$ & $\begin{array}{l}\text { Placebo twice } \\
\text { daily }(n=30)\end{array}$ & $\begin{array}{l}\text { BW, BMI, WC, FBS, } \\
\text { LDL, HDL, TC, TG, } \\
\text { LFT, RFTs, AEs }\end{array}$ & 5 \\
\hline
\end{tabular}

DRCT, double blind randomized controlled trial; BMI, body mass index; BW, body weigh; WC, waist circumference; SBP, systolic blood pressure; DBP, diastolic blood pressure; FBS, fasting blood sugar; LDL, low-density lipoprotein; HDL, high-density lipoprotein; TC, total cholesterol; TG, triglyceride; LFT, liver function test; RFTs, renal function test; AEs, adverse events

\section{TABLE 2: RISK OF BIAS}

\begin{tabular}{|c|c|c|c|c|c|c|c|c|}
\hline Studies & 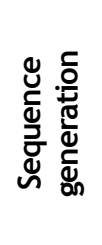 & 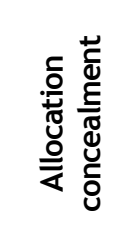 & 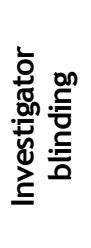 & 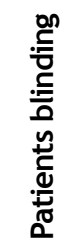 & 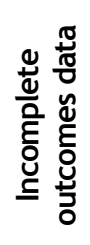 & 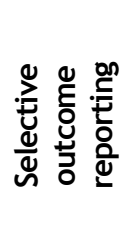 & 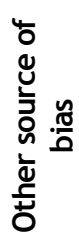 & 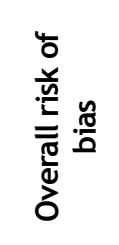 \\
\hline Stern et al. 2013A $\mathrm{A}^{[13]}$ & Low & Low & Low & Low & Low & Low & Low & Unclear \\
\hline Stern et al. 2013B ${ }^{[14]}$ & Low & Unclear & Low & Low & Low & Low & Low & Unclear \\
\hline Kudiganti et al. 2016[5] & Low & Low & Low & Low & Low & Low & Low & Unclear \\
\hline
\end{tabular}


anthropological parameter. The pooled effect from meta-analysis demonstrated that clinical efficacy on body weight was significantly better than those of controlled treatment (WMD $=-3.84,95 \%$ CI was -3.98 to -3.70$)$ with no evidence of heterogeneity among studies $\left(\mathrm{I}^{2}=32 \%, \mathrm{p}=0.23\right)$. Moreover, $S$. indicus and G. mangostana product decreased $\mathrm{BMI}(\mathrm{WMD}=-1.56$, $95 \%$ CI was -1.65 to -1.47 ) and waist circumference $(\mathrm{WMD}=-5.90,95 \%$ CI was -6.36 to -5.43 ). However, heterogeneity was observed in these outcomes.

S. indicus and G. mangostana product reduced LDL, total cholesterol and triglyceride level significantly $(\mathrm{WMD}=-10.74,95 \% \mathrm{CI}$ was -19.04 to $-2.44 ;-22.05$ -32.33 to $-11.76 ;-27.40-30.55$ to -24.24 , respectively). Moreover, there was significant increase in HDL level (WMD $2.32 \mathrm{mg} / \mathrm{dl} ; 95 \%$ CI 0.56, 4.07) and there was evidence of heterogeneity (Table 3 ).

Two trials ${ }^{[12,13]}$ contributed to data on the effect of $S$. indicus and G. mangostana product on blood pressure. $S$. indicus and $G$. mangostana product was not superior to comparators in systolic blood pressure (WMD: -1.81; $95 \%$ CI -4.01 to 0.38 ), diastolic blood pressure (WMD: -2.03 ; $95 \%$ CI -5.34 to 1.28 ) and pulse rate (WMD: $0.61 ; 95 \% \mathrm{CI}-1.58$ to 2.79$)$. A statistically significant heterogeneity was detected with these 3 outcomes (Table 3).
The effect of $S$. indicus and $G$. mangostana on fasting blood glucose (FBS) indicated a non-significant reduction in FBS level was observed in participants who were administrated herbal product (WMD: -1.53; $95 \%$ CI -5.15 to 2.08). A significant heterogeneity was detected in this outcome (Table 3 ).

There were 208 participants in 3 trials that compared liver function tests. The results were found to be significantly heterogeneous. Therefore, the random effects model was used in combining the results among trials. The results showed that $S$. indicus and $G$. mangostana products reduced both SGOT and SGPT levels. The pooled estimate of WMD effects were -1.54 $\mathrm{U} / 1(95 \% \mathrm{CI}-2.52$ to -0.57$)$ and $-1.56 \mathrm{U} / 1(95 \% \mathrm{CI}$ -1.65 to -1.47$)$, respectively. However, there were no significant difference between 152 participants in two trials in blood urea nitrogen (BUN) level (WMD 1.57; $95 \%$ CI -1.50 to 4.64 ) and serum creatinine (WMD $0.50 ; 95 \%$ CI -0.05 to 0.15$)$. Heterogeneity was observed in these outcomes (Table 4).

Adverse events were reported in 2 randomized clinical trials (RCTs ${ }^{[5,14]}$. Among these, there were no differences in the adverse effects of $S$. indicus and G. mangostana product compared to placebo (RR 0.84; $95 \%$ CI 0.42 , $1.67 ; p=0.80)$. Heterogeneity was not observed in this

TABLE 3: META-ANALYSIS OF EFFECTS OF S. INDICUS AND G. MANGOSTANA ON ALL OUTCOMES

\begin{tabular}{|c|c|c|c|c|c|}
\hline \multirow{2}{*}{ Outcomes (ref) } & \multirow{2}{*}{$\begin{array}{l}\text { No. of } \\
\text { studies }\end{array}$} & \multicolumn{2}{|l|}{ Outcome difference } & \multicolumn{2}{|c|}{ Heterogeneity } \\
\hline & & Mean $(95 \% \mathrm{Cl})$ & p-value & $\mathrm{I}^{2}$ & p-value \\
\hline \multicolumn{6}{|c|}{ Anthropological parameter ${ }^{[5,13,14]}$} \\
\hline Body weight & 3 & $-3.84 \mathrm{~kg}(-3.98$ to -3.70$)$ & $<0.00001$ & $32 \%$ & 0.23 \\
\hline Body mass index & 3 & $-1.56 \mathrm{~kg} / \mathrm{m}^{2}(-1.65$ to -1.47$)$ & $<0.00001$ & $63 \%$ & 0.07 \\
\hline \multirow[t]{2}{*}{ Waist circumference } & 3 & $-5.90 \mathrm{~cm}(-6.36$ to -5.43$)$ & $<0.00001$ & $68 \%$ & 0.05 \\
\hline & & Lipid profile ${ }^{[5,13,14]}$ & & & \\
\hline LDL & 3 & $-10.74 \mathrm{mg} / \mathrm{dl}(-19.04$ to -2.44$)$ & 0.01 & $99 \%$ & $<0.00001$ \\
\hline HDL & 3 & $2.32 \mathrm{mg} / \mathrm{dl}(0.56$ to 4.07$)$ & 0.01 & $98 \%$ & $<0.00001$ \\
\hline Total cholesterol & 3 & $-22.05 \mathrm{mg} / \mathrm{dl}(-32.33$ to -11.76$)$ & $<0.0001$ & $98 \%$ & $<0.00001$ \\
\hline \multirow[t]{2}{*}{ Triglyceride } & 3 & $-27.40 \mathrm{mg} / \mathrm{dl}(-30.55$ to -24.24$)$ & $<0.0001$ & $74 \%$ & 0.02 \\
\hline & & Blood pressure $\mathrm{e}^{[13,14]}$ & & & \\
\hline Systolic blood pressure & 2 & $-1.81 \mathrm{mmHg}(-4.01$ to 0.38$)$ & 0.23 & $98 \%$ & $<0.0001$ \\
\hline Diastolic blood pressure & 2 & $-2.03 \mathrm{mmHg}(-5.34$ to 1.28$)$ & 0.23 & $98 \%$ & $<0.0001$ \\
\hline \multirow[t]{2}{*}{ Pulse rate } & 2 & $0.61(-1.58$ to 2.79$)$ & 0.59 & $97 \%$ & $<0.0001$ \\
\hline & & Blood glucose $\mathrm{e}^{[5,13,14]}$ & & & \\
\hline Fasting blood sugar & 3 & $-1.53 \mathrm{mg} / \mathrm{dl}(-5.15$ to 2.08$)$ & 0.41 & $98 \%$ & $<0.0001$ \\
\hline
\end{tabular}

TABLE 4: META-ANALYSIS OF EFFECTS OF S. INDICUS AND G. MANGOSTANA ON LABORATORY TEST

\begin{tabular}{|c|c|c|c|c|c|}
\hline \multirow{2}{*}{ Outcomes } & \multirow{2}{*}{ No. of studies } & \multicolumn{2}{|c|}{ Outcome difference } & \multicolumn{2}{|c|}{ Heterogeneity } \\
\hline & & Mean $(95 \% \mathrm{Cl})$ & p-value & $I^{2}$ & p-value \\
\hline $\mathrm{SGOT}^{[5,13,14]}$ & 3 & $-1.54 \mathrm{U} / \mathrm{l}(-2.52$ to -0.57$)$ & 0.002 & $91 \%$ & $<0.00001$ \\
\hline SGPT ${ }^{[5,13,14]}$ & 3 & $-1.56 \mathrm{U} / \mathrm{l}(-1.65$ to -1.47$)$ & $<0.00001$ & $63 \%$ & 0.07 \\
\hline$B U N^{[5,14]}$ & 2 & $1.57 \mathrm{mmol} / \mathrm{l}(-1.50$ to 4.64$)$ & 0.32 & $100 \%$ & $<0.00001$ \\
\hline $\mathrm{SCr} \mathrm{r}^{[5,14]}$ & 2 & $0.05 \mathrm{mg} / \mathrm{dl}(-0.05$ to 0.15$)$ & 0.31 & $99 \%$ & $<0.00001$ \\
\hline
\end{tabular}




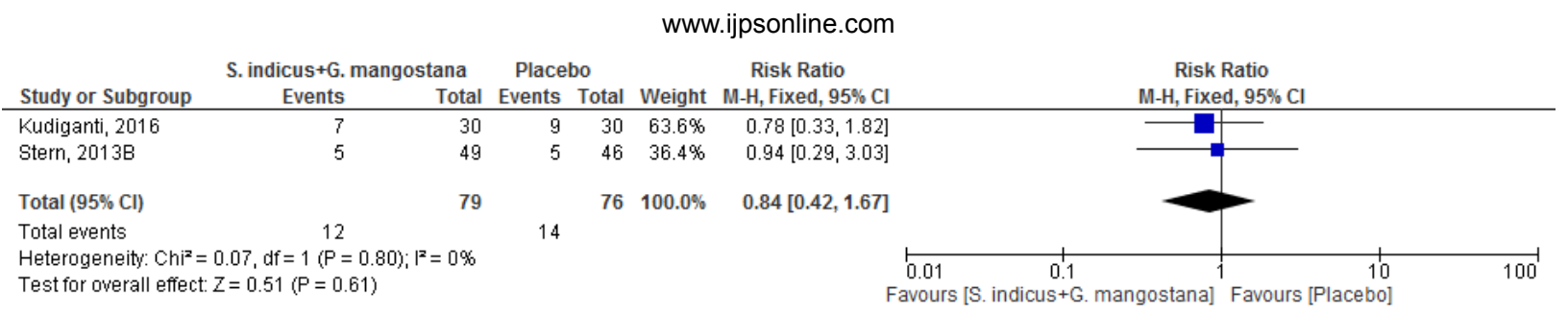

Fig. 2: Meta-analysis of effects of $S$. indicus and $G$. mangostana on adverse effects

outcome. In summary, serious or intolerant adverse events were low compared to placebo (fig. 2).

Sensitivity analyses were performed by one-removal study analysis. After removal of studies, the effects of $S$. indicus and G. mangostana product on all outcomes were not changed from the pooled data outcomes. Funnel plots were used in investigate the publication bias in all outcomes. The results indicated no publication bias.

This study is the first systematic review and metaanalysis to determine the efficacy and safety of $S$. indicus and G. mangostana in obese participants for improving anthropological parameters, lipid profiles, blood glucose and blood pressure. This metaanalysis results suggested significant reduction of anthropological effects including body weight, BMI and waist circumference. Moreover, $S$. indicus and G. mangostana product also decreased LDL, TC, TG and increased HDL significantly. Present study found that $S$. indicus and G. mangostana products exhibited fewer adverse effects with no statistical difference compared to placebo. The results of subgroup analysis did not show any significant difference to the pooled estimation.

The possible effects of $S$. indicus and G. mangostana in the reduction of anthropological outcomes comprise multiple mechanisms. For instance, $S$. indicus and $G$. mangostana effects on the 3T3-L1 adipocytes resulted in a marked reduction in PPAR $\gamma$, cluster of differentiation 36 (CD36), and adipocyte-differentiation related protein (ADRP) level. In another mechanism, S. indicus and G. mangostana also reduced expression of perilipin protein on the surface of lipid droplets ${ }^{[8]}$. From the proposed mechanisms, $S$. indicus and G. mangostana may attenuate fat accumulation by partially blocking adipogenesis and fat uptake, and by rendering lipid droplets more susceptible to lipases ${ }^{[6,15]}$. Additionally, $S$. indicus and G. mangostana extract also increase fat metabolism resulting in significant weight loss ${ }^{[16]}$.

In terms of lipid effect, Claycombe et al.$^{[17]}$ demonstrated that $S$. indicus and G. mangostana extract inhibited adipogenic differentiation and boosted lipid breakdown in mature fat cells and affected hormones, which control lipogenesis in adipocytes through directly regulating the key enzymes of the lipogenic pathway. Moreover, previous reports of the product activated AMPK associated with the stimulation of fatty acid oxidation, glucose uptake by muscle cells, and inhibition of cholesterol and triglyceride synthesis ${ }^{[18,19]}$.

Most of included trials indicated that $S$. indicus and G. mangostana product were safe during the period of study, 8-16 w. Similar to previous animal studies, the product showed no relevant toxicological effects. In a chronic toxicity study in rats, ethanol extract of mangosteen pericarp, given orally at doses of 10 to $1000 \mathrm{mg} / \mathrm{kg}$ for $6 \mathrm{mo}$, showed no overt toxicity or abnormal hematological effects, liver and kidney function tes ${ }^{[8]}$. However, this systematic review and meta-analysis revealed that SGOT, SGPT decreased significantly after administering $S$. indicus and G. mangostana products. Elevation of liver function enzymes, especially SGPT, caused by liver damage contributes to fatty liver. Long term clinical outcomes of high SGPT were not observed. With maximum duration of trial, $13 \mathrm{w}$ was relatively short to detect any clinical benefit.

The strength of this study is a comprehensive summary of the effects of S. indicus and G. mangostana products, undertaken in accordance with a high standard of systematic review and meta-analysis and reported in alignment with PRISMA ${ }^{[10]}$. The meta-analysis of RCT is at the top in the hierarchy of the clinical evidence. All of the included studies were high quality. Indeed, this is the first systematic review and meta-analysis of RCT investigating efficacy and safety of $S$. indicus and G. mangostana product at $800 \mathrm{mg} / \mathrm{d}$ on anthropological, lipid profile, blood glucose and blood pressure. Although studies with the same types of comparisons, and time to follow-up (8-16 w) without language restriction were included in this meta-analysis, efficacy and safety of $S$. indicus and G. mangostana product is quite consistent across all studies. This implied that our result can be generalized to wider clinical practices.

Even though the evidence on clinical effects of $S$. indicus and G. mangostana product on all outcomes is quite consistent across studies, a number of limitations 
should be mentioned. Only 3 RCT met the inclusion criteria and there were small numbers of participants in individual studies.

Based on current evidence, combinations S. indicus and G. mangostana are found to be effective and safe in obese participants, however, well-designed, large, multicenter, randomized placebo- or active-controlled trials investigating long term effects of $S$. indicus and G. mangostana product on cardiomatabolic outcomes are needed to further support current evidence.

\section{Acknowledgements:}

We would like to thank Prof. Arian Roderick Plant for language assistance

\section{Conflict of interest:}

The authors declare that they have no conflict of interest.

\section{REFERENCES}

1. Mathers CD, Loncar D. Projections of global mortality and burden of disease from 2002 to 2030. PLoS Med 2006;3:e442.

2. Eckel RH, Kahn R, Robertson RM, Rizza RA. Preventing cardiovascular disease and diabetes: A call to action from the American Diabetes Association and the American Heart Association. Circulation 2006;113:2943-6.

3. Buttar HS, Li T, Ravi N. Prevention of cardiovascular diseases: Role of exercise, dietary interventions, obesity and smoking cessation. Exp Clin Cardiol 2005;10(4):229-49.

4. Schwalm JD, McKee M, Huffman MD, Yusuf S. Resource Effective Strategies to Prevent and Treat Cardiovascular Disease. Circulation 2016;133(8):742-55.

5. Kudiganti V, Kodur RR, Kodur SR, Halemane M, Deep DK. Efficacy and tolerability of Meratrim for weight management: a randomized, double-blind, placebo-controlled study in healthy overweight human subjects. Lipids Health Dis 2016;15(1):136.

6. Jones JR, Barrick C, Kim KA, Lindner J, Blondeau B, Fujimoto $\mathrm{Y}$, et al. Deletion of PPARgamma in adipose tissues of mice protects against high fat diet-induced obesity and insulin resistance. Proc Natl Acad Sci 2005;102:6207-12.
7. Ameer F, Scandiuzzi L, Hasnain S, Kalbacher H, Zaidi N. De novo lipogenesis in health and disease. Metabolism 2014;63(7):895-902

8. Saiyed ZM, Sengupta K, Krishnaraju AV, Trimurtulu G, Lau FC, Lugo JP. Safety and toxicological evaluation of Meratrim ${ }^{\circledR}$ : an herbal formulation for weight management. Food Chem Toxicol 2015;78:122-9.

9. Higgins JP, Altman DG, Gøtzsche PC, Jüni P, Moher D, Oxman $\mathrm{AD}$, et al. The Cochrane Collaboration's tool for assessing risk of bias in randomised trials. BMJ 2011;343:d5928.

10. Moher D, Liberati A,TetzlaffJ, Altman D. Preferred reporting items for systematic reviews and meta-analyses: the PRISMA statement. Ann Intern Med 2009;151(4):264-8.

11. Higgins J, Thompson S, Deeks J, Altman D. Measuring inconsistency in meta-analyses. BMJ 2003; 327(7414):557-60.

12. Peters J, Sutton A, Jones D, Abrams K, Rushton L. Comparison of two methods to detect publication bias in meta-analysis. JAMA 2006;295(6):676-80.

13. Stern JS, Peerson J, Mishra AT, Sadasiva Rao MV, Rajeswari KP. Efficacy and tolerability of a novel herbal formulation for weight management. Obesity 2013; 21:921-7.

14. Stern JS, Peerson J, Mishra AT, Mathukumalli VS, Konda PR. Efficacy and tolerability of an herbal formulation for weight management. J Med Food 2013;16(6):529-37.

15. Bonen A, Tandon NN, Glatz JF, Luiken JJ, Heigenhauser GJ. The fatty acid transporter FAT/CD36 is upregulated in subcutaneous and visceral adipose tissues in human obesity and type 2 diabetes. Int J Obes 2006;30:877-83.

16. Yamauchi T, Kamon J, Waki H, Terauchi Y, Kubota N, Hara $\mathrm{K}$, et al. The fat-derived hormone adiponectin reverses insulin resistance associated with both lipoatrophy and obesity. Nat Med 2001;7:941-6.

17. Claycombe KJ, Jones BH, Standridge MK, Guo Y, Chun JT, Taylor JW, et al. Insulin increases fatty acid synthase gene transcription in human adipocytes. Am J Physiol 1998;274(5):253-9.

18. Goodyear LJ.AMP-activated protein kinase: a critical signaling intermediary for exercise- stimulated glucose transport? Exer Sport Sci Rev 2000;28(3):113-6.

19. Hardie DG. AMP-activated protein kinase: a master switch in glucose and lipid metabolism. Rev Endocr Metab Disord 2004;5(2):119-25. 